\title{
Synthesis of a head-to-tail-type cyclodextrin-based insulated molecular wire.
}

\section{$\operatorname{AUTHOR}(\mathrm{S}):$}

Terao, Jun; Ikai, Kazuhiro; Kambe, Nobuaki; Seki, Shu; Saeki, Akinori; Ohkoshi, Kento; Fujihara, Tetsuaki; Tsuji, Yasushi

\section{CITATION:}

Terao, Jun ...[et al]. Synthesis of a head-to-tail-type cyclodextrin-based insulated molecular wire.. Chemical communications 2011, 47(24):

6816-6818

\section{ISSUE DATE:}

2011-06-28

URL:

http://hdl.handle.net/2433/156790

\section{RIGHT:}

(c) The Royal Society of Chemistry 2011; この論文は出版社版でありませ ん。引用の際には出版社版をご確認ご利用ください。; This is not the published version. Please cite only the published version. 


\title{
Synthesis of head-to-tail-type cyclodextrin-based insulated molecular wire
}

\author{
Jun Terao, ${ }^{* a}$ Kazuhiro Ikai, ${ }^{b}$ Nobuaki Kambe, ${ }^{b}$ Shu Seki, ${ }^{* b}$ Akinori Saeki, ${ }^{b}$ Kento Ohkoshi, ${ }^{c}$ \\ Tetsuaki Fujihara, ${ }^{a}$ Yasushi Tsuji ${ }^{a}$
}

\author{
Received (in $X X X, X X X)$ Xth $X X X X X X X X X 20 X X$, Accepted Xth XXXXXXXXX 20XX \\ DOI: $10.1039 / b 000000 x$
}

We developed a new method for synthesizing an organicsoluble insulated molecular wire (IMW) using permethylated cyclodextrin (PMCD). The IMW obtained using this method 10 is highly soluble in a variety of organic solvents and has a high covering ratio, regioregularity, rigidity, photoluminescence efficiency, and interchain hole mobility.

Insulated molecular wires (IMWs) have generated considerable interest because their conjugated polymer units are insulated by a 15 protective sheath that limits the $\pi-\pi$ interaction, thereby increasing the interchain charge mobility, fluorescence, solubility, and chemical stability of these polymers compared to those of the corresponding uninsulated $\pi$-conjugated polymers. ${ }^{1}$ Moreover, IMWs have attracted considerable attention owing to their ${ }_{20}$ potential applicability as wiring materials for next-generation monomolecular electronic devices. ${ }^{2}$ Additionally, methods for threading $\pi$-conjugated polymers through cyclodextrins (CDs) have been researched extensively to enable the synthesis of $\mathrm{CD}$ based IMWs and to investigate their commercial availability and 25 efficacy of inclusion through hydrophilic-hydrophobic interactions between CD and organic molecules. ${ }^{3-6}$ These IMWs are soluble in water but generally insoluble in organic solvents ${ }^{7}$ because the conjugated chains are insulated with hydrophilic CDs. In addition, partially uninsulated sites and a considerable amount 30 of residual water molecules exist, which reduce the potential of IMWs as electronic materials. To overcome these obstacles, we developed a new method for synthesizing an organic soluble IMW by Glaser polymerization of lipophilic permethylated $\alpha$ cyclodextrin (PMCD)-based rotaxane as a monomer. ${ }^{8}$ The IMW 35 formed using this method has diyne bonds, which reduce the charge mobility in the $\pi$-conjugated polymer chain by the reduction of the effective conjugation length. Furthermore, to extend the effective conjugation length of the IMW backbone, we developed a method for synthesizing a diyne-bond-free IMW 40 containing polyphenylene-ethynylene (PPE) as the polymer backbone via the Sonogashira co-polymerization of $p$ diiodobenzene with pseudo-linked [3] rotaxane containing alkynyl groups at both ends. ${ }^{9}$ In the present study, we applied these methods to synthesize a head-to-tail-type PMCD-based IMW 45 (head-tail direction of the upper rim of adjacent CDs) via Sonogashira polymerization of a pseudo-linked [2]rotaxane containing iodo and alkynyl groups at both ends, as a monomer. Our aim was to add regioregularity, increase the covering ratio of
PMCDs against $\pi$-conjugated polymer chains, and introduce a 50 PPE unit as the main chain unit of the IMW (Scheme 1).

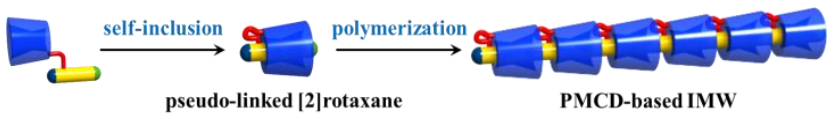

Scheme 1 Synthetic route to head-to-tail-type cyclodextrin-based insulated molecular wire.

$55 \pi$-Conjugated guest-linked PMCD 5 was synthesized from 6$O$-monotosyl PMCD $\mathbf{1}^{10}$ in $36 \%$ overall yield via five steps, as shown in Scheme 2. The reaction of $\mathbf{1}$ with 2-iodo-5-nitrophenol resulted in an iodobenzene-linked PMCD 2. Sonogashira coupling of $\mathbf{2}$ with (4-ethynylphenylethynyl)trimethylsilane 60 followed by the reduction of the nitro group gave an ethynylphenylethynyl-linked PMCD 4 via two steps. 4 was then treated with $\mathrm{NaNO}_{2}$ and KI, followed by the deprotection of the trimethylsilyl group to give $\mathbf{5}$.
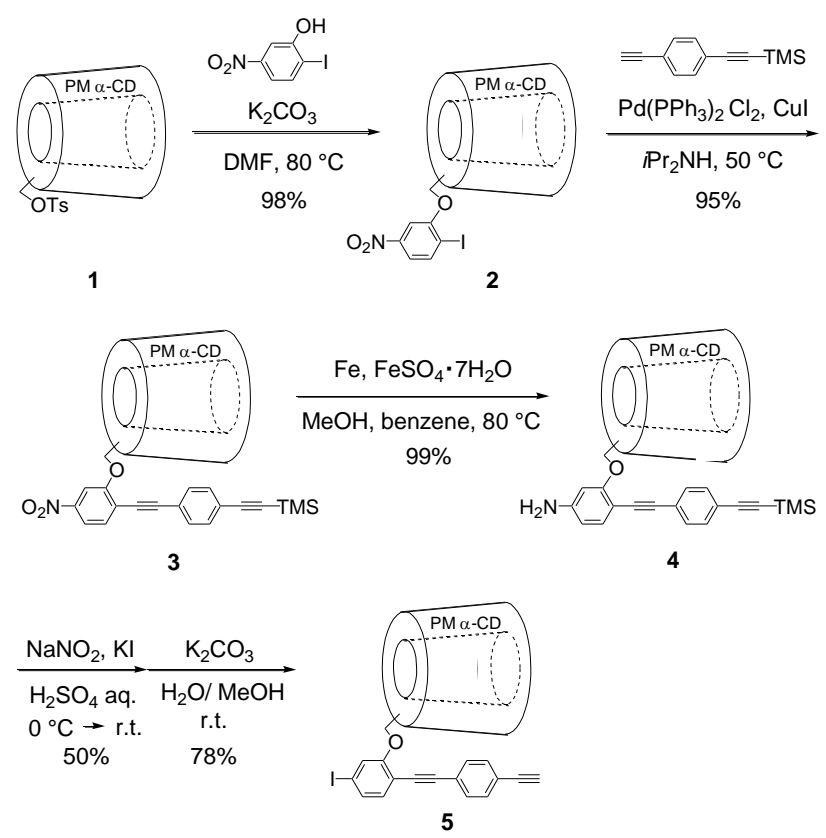

${ }_{65}$ Scheme 2 Synthesis of $\pi$-conjugated guest-linked permethylated $\alpha$ cyclodextrin $\mathbf{5}$. 
The intramolecular self-inclusion phenomenon of $\pi$-conjugated guest-linked PMCD 5 has been confirmed by the space-filling model and examined by ${ }^{1} \mathrm{H}$ NMR using different solvents and concentrations. ${ }^{11}$ As shown in Figure 1, NMR spectral analysis of ${ }_{5} \mathbf{5}$ in $\mathrm{CDCl}_{3}$ at room temperature revealed that the $\pi$-conjugated guest moiety was excluded from the cavity of the PMCD. The spectrum in $\mathrm{CD}_{3} \mathrm{OD}$ at room temperature indicates the presence of a mixture of $\mathbf{5}$ and its inclusion complex (linked [2]rotaxane) ${ }^{12}$ 6. When we used $\mathrm{D}_{2} \mathrm{O}: \mathrm{CD}_{3} \mathrm{OD}=1: 3$ as a solvent, 5 was 10 completely converted to $\mathbf{6}$. The structure of the inclusion complex 6 was characterized by 2D ROESY NMR (Fig. S1 in the Electronic Supplementary Information). This was done because there are NOEs between the protons in the $\pi$-conjugated guest moiety and the $\mathrm{H}_{3}$ and $\mathrm{H}_{5}$ protons in the interior of the PMCD.
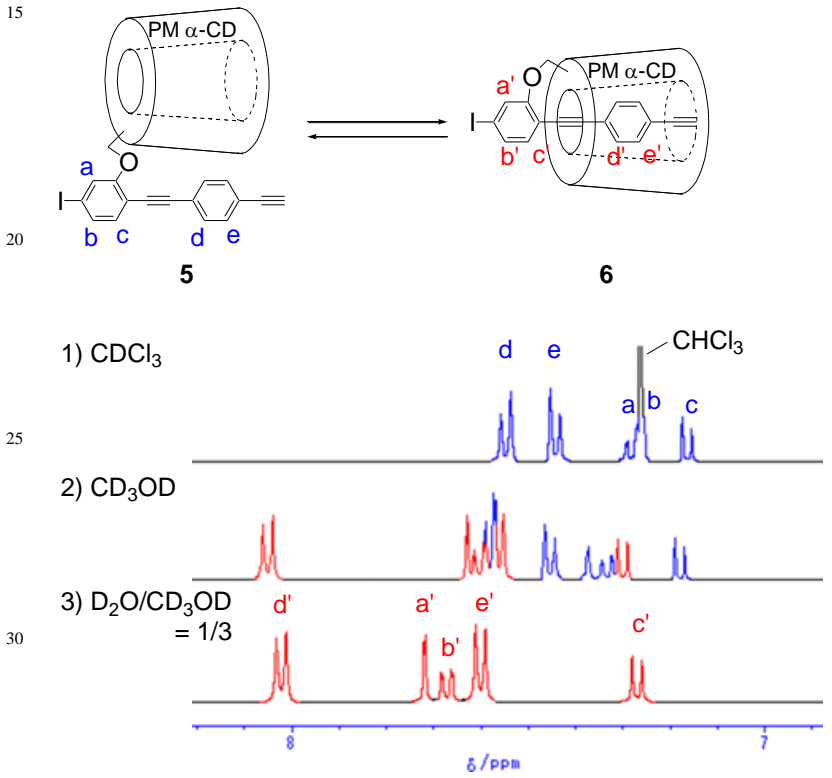

${ }_{35}$ Fig. 1 Aromatic region of ${ }^{1} \mathrm{H}$ NMR spectra of $\mathbf{5}$ in different solvents. (1) $\mathrm{CDCl}_{3}$, (2) $\mathrm{CD}_{3} \mathrm{OD}$, and (3) $\mathrm{D}_{2} \mathrm{O}: \mathrm{CD}_{3} \mathrm{OD}=1: 3$.

Next, we conducted the polymerization of $\mathbf{6}$ as a monomer under Sonogashira coupling conditions in $\mathrm{H}_{2} \mathrm{O}: \mathrm{CH}_{3} \mathrm{OH}=1: 3$. ${ }_{40} \mathrm{GPC}$ analysis revealed that monomer 6 mostly disappeared after $24 \mathrm{~h}$ and the formation of IMW 7 was confirmed (Fig. S2). The MALDI-TOF mass spectrum of 7 provided additional evidence for the structural authenticity of this compound (Fig. S3). As expected, all of the observed peaks in the mass spectrum 45 corresponded to singly charged molecular ions containing more than seven repeating units. Studies conducted using space-filling models revealed that the covering ratio of PMCDs in the $\pi$ conjugated backbone of 7 was approximately $82 \%$ (Fig. S4). The IMW 7 obtained as described above was soluble in organic 50 solvents such as ethyl acetate $(22 \mathrm{mg} / \mathrm{mL})$, chloroform (38 $\mathrm{mg} / \mathrm{mL}$ ), toluene (3 $\mathrm{mg} / \mathrm{mL})$, and dimethylformamide (48 $\mathrm{mg} / \mathrm{mL}$ ), because the $\pi$-conjugated chain of IMW 7 was coated with highly organic-soluble PMCDs. The uninsulated polymer 8 was synthesized as a reference by polymerization of $\mathbf{5}$ in a 55 lipophilic solution $\left(i-\mathrm{Pr}_{2} \mathrm{NH}\right)$ under polymerization conditions similar to those used for the synthesis of 7 . The chemical shifts between monomers and the corresponding polymers in the ${ }^{1} \mathrm{H}$ NMR spectra were well correlated. The peaks in the ${ }^{1} \mathrm{H}$ NMR spectra of 5 and $\mathbf{6}$ were broader than those in the ${ }^{1} \mathrm{H}$ NMR spectra
60 of the corresponding polymers $\mathbf{8}$ and $\mathbf{7}$; this indicated that the inclusion or exclusion complex structure was maintained during each polymerization reaction (Fig. S5). The $M_{\mathrm{w}}$ values of polymers $\mathbf{7}$ and $\mathbf{8}$, which were estimated using polystyrene as the calibration standard, were $3.2 \times 10^{4}(\tilde{n}=22)$ and $4.5 \times 10^{4}(\tilde{n}=$ $\left.{ }_{65} 32\right)$, respectively.

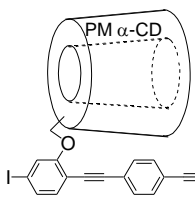

$\mathrm{Pd}\left(\mathrm{PPh}_{3}\right)_{2} \mathrm{Cl}_{2}$

Cul, $\mathrm{K}_{2} \mathrm{CO}_{3}$

$\mathrm{Pr}_{2} \mathrm{NH}, 25^{\circ} \mathrm{C}$

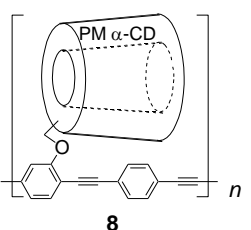

$\mathrm{H}_{2} \mathrm{O} / \mathrm{CH}_{3} \mathrm{OH}$

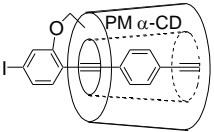

6

$\mathrm{Pd}(\mathrm{OAc})_{2}$, TXPTS $\mathrm{Cul}, \mathrm{K}_{2} \mathrm{CO}_{3}$ $\mathrm{H}_{2} \mathrm{O} / \mathrm{CH}_{3} \mathrm{OH}, 25^{\circ} \mathrm{C}$
Scheme 3 Synthesis of insulated and uninsulated polymers.

70 The absorption and emission wavelength of $\mathbf{5}, \mathbf{7}$, and 8 in $\mathrm{CHCl}_{3}$ solution are shown in Table 1. Elongation of the $\pi$ conjugated backbone from monomer $\mathbf{5}$ to polymer $\mathbf{8}$ resulted in a red shift by about $40 \mathrm{~nm}$. According to the spectra obtained from $\mathbf{7}$ and 8, slight blue shifts occurred in the absorption and the 75 emission spectra of 7 . These shifts suggest that the effective conjugation length of the PPE unit was shortened by insulation of the PMCDs. As expected, considerable enhancement of the fluorescence in the solid state was observed in 7 compared to the corresponding uninsulated polymer 8. These findings indicate 80 that the insulation of $\pi$-conjugated units by PMCDs limits the $\pi-\pi$ interaction and enhances the fluorescence properties of the PPE units.

Table 1 Absorption and emission wavelength of 5, 7, and 8 and ${ }_{85}$ fluorescence quantum yields of $\mathbf{7}$ and $\mathbf{8}{ }^{a}$

\begin{tabular}{cccc}
\hline Compound & $\begin{array}{c}\text { Absorption } \\
\left(\lambda_{\max } / \mathrm{nm}\right)\end{array}$ & $\begin{array}{c}\text { Emission } \\
\left(\lambda_{\max } / \mathrm{nm}\right)\end{array}$ & $\Phi_{\text {solid }}$ \\
\hline $\mathbf{5}$ & 352 & 389,408 & - \\
$\mathbf{7}$ & 382 & 416,439 & 0.34 \\
$\mathbf{8}$ & 392 & 423,446 & 0.13
\end{tabular}

${ }^{a}$ The spectra were recorded in $\mathrm{CHCl}_{3}$. The absolute quantum yields were determined using a calibrated integrating-sphere system.

To evaluate the covering effect of PMCD, we calculated the persistence lengths $(q)$ of insulated polymer 7 and uninsulated 90 polymer $\mathbf{8}$ using the model of an unperturbed worm-like cylinder. ${ }^{13}$ The calculated $q$ values of $\mathbf{7}$ and $\mathbf{8}$ were $3.41 \mathrm{~nm}$ and $1.79 \mathrm{~nm}$, respectively, indicating that the rigidity of the PPE chain in 7 can be largely attributed to the intramolecular inclusion of the polymer main chain into the PMCD cavity (Fig. S6).

95 We next examined the potential for charge mobility of the insulated molecular wire in the solid state by simultaneously 
performing time-resolved microwave conductivity (TRMC) and transient absorption spectroscopy (TAS) measurements. ${ }^{14}$ Complete contactless measurement of the intra-molecular mobility was performed by combining the electrodeless transient 5 conductivity measurement by TRMC (Fig. 2a and 2b) with the clear transient optical absorption spectrum of the radical cations of 7 (Fig. 2c and 2d). The identical kinetic traces observed for the conductivity and absorption transients in Fig. $2 \mathrm{a}$ and $2 \mathrm{~d}$ strongly suggest that the major charge carriers are positive holes. 10 According to the time course of these measurements, with a molar extinction coefficient $\varepsilon+=3.5 \times 10^{5} \mathrm{~cm}^{-1} \mathrm{~mol}^{-1} \mathrm{dm}^{3}$ for the radical cation of 7 , the minimum value of the anisotropic hole mobility in the PPE backbone of this IMW was estimated to be $0.7 \mathrm{~cm}^{2} / \mathrm{Vs}$. This value was fairly high, higher than that of the 15 uninsulated polymer $8\left(0.2 \mathrm{~cm}^{2} / \mathrm{Vs}\right)$, and comparable to that in polythiophene-based IMW. ${ }^{15}$ It should be noted that the hole mobility in the PPE backbone of this insulated molecular wire showed a low decay rate constant, which was likely due to the extremely long lifetime of the holes on the $\pi$ conjugated core; on 20 the other hand, rapid charge recombination was observed in the case of the uninsulated polymer $\mathbf{8}$. These results suggest that PMCD protects the holes in the $\pi$-conjugated core from the charge recombination process.
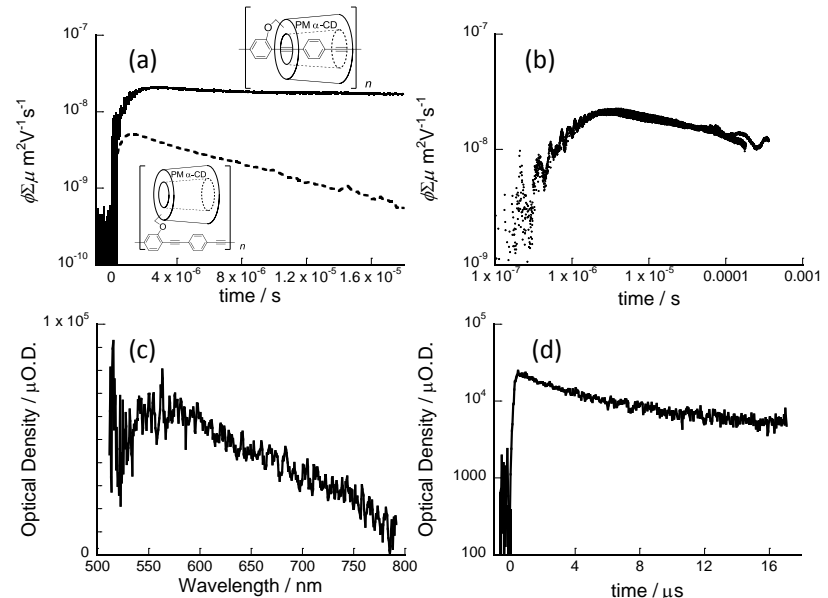

Fig. 2 (a) Conductivity transients observed upon excitation of $355 \mathrm{~nm}$ at $7.3 \times 10^{15}$ photons $\mathrm{cm}^{-2}$ in a $2.3 \mu \mathrm{m}$ thick casted film of 7 (solid) and 8 (dashed) under an air at $293 \mathrm{~K}$. (b) The transient with extra-long life time of radical cations of 7 was monitored over $1 \mathrm{~ms}$. (c) The transient 30 absorption spectrum of 7 in thin solid film was observed at $10 \mu$ s after excitation of $355 \mathrm{~nm}$ at $5.5 \times 10^{16}$ photons $\mathrm{cm}^{-2}$. (d) The kinetic trace at $570 \mathrm{~nm}$

\section{Conclusions}

We developed a new method for the synthesis of highly organic35 soluble IMW with PMCD lines in the same direction by carrying out Sonogashira polymerization of linked [2]rotaxane containing iodo and alkynyl groups at both ends of a $\pi$-conjugated guest. The obtained insulated molecular wires had high solubility in organic solvents, high covering ratio, rigidity, and 40 photoluminescence efficiency. Furthermore, they showed high charge mobility in the solid state. Experiments are currently under way to evaluate the behavior of these new materials in molecular electronics.

\section{${ }_{45}$ Notes and references}

${ }^{a}$ Department of Energy and Hydrocarbon Chemistry, Graduate School of Engineering, Kyoto University, and PRESTO, Japan Science and Technology Agency (JST), Kyoto 615-8510, Japan, Fax: +81-75-3832516; Tel: +81-75-383-2514; E-mail: terao@scl.kyoto-u.ac.jp

${ }_{50}{ }^{b}$ Department of Applied Chemistry Graduate School of Engineering, Osaka University, and PRESTO, Japan Science and Technology Agency (JST), Yamadaoka 2-1, Suita, Osaka 565-0871, Japan, Tel: +81-6-68794586; E-mail: seki@chem.eng.osaka-u.ac.jp

${ }^{c}$ Department of Polymer Chemistry, Tokyo Institute of Technology, 55 Ookayama, Meguro-ku, Tokyo 152-8552, Japan.

$\dagger$ Electronic Supplementary Information (ESI) available: See DOI: $10.1039 / \mathrm{b} 000000 \mathrm{x} /$

1 For recent reviews of insulated molecular wires, see: (a) M. J. 60 Frampton and H. L. Anderson, Angew. Chem. Int. Ed., 2007, 46, 1028-1064; (b) G. Wenz. In Inclusion Polymers, Springer, Verlag (2009)

2 Recently we have developed a molecular interconnecting method between nanoelectrodes by using polyrotaxane as an insulated molecular wire, see: M. Taniguchi, Y. Nojima, K. Yokota, J. Terao, K. Sato, N. Kambe and T. Kawai, J. Am. Chem. Soc., 2006, 128, 15062-15063.

3 For recent reviews, see: (a) G. Wenz, B.-H. Han and A. Müller, Chem. Rev., 2006, 106, 782-817; (b) A. Harada, Y. Takashima and H. Yamaguchi, Chem. Soc. Rev., 2009, 38, 875-882.

4 For the synthesis of CD-based IMWs involves the threading of $\pi$ conjugated polymers through CDs, see: (a) K. Yoshida, T. Shimomura, K. Ito and R. Hayakawa, Langmuir, 1999, 15, 910-913; (b) I. Yamaguchi, K. Kashiwagi and T. Yamamoto, Macromol. Rapid Commun., 2004, 25, 1163-1166.

5 For the synthesis of CD-based IMWs involves the polymerization of pseudorotaxane, see: M. van den Boogaard, G. Bonnet, P. Van't Hof, Y. Wang, C. Brochon, P. van Hutten, A. Lapp and G. Hadziioannou, Chem. Mater., 2004, 16, 4383-4385.

806 For the synthesis of CD-based IMWs involves the copolymerization of pseudorotaxane with linker molecules, see: (a) P. N. Taylor, M. J. O'Connell, L. A. McNeill, M. J. Hall, R. T. Aplin and H. L. Anderson, Angew. Chem. Int. Ed., 2000, 39, 3456-3460; (b) K. Shinohara, T. Suzuki, T. Kitami and S. Yamaguchi, J. Polym. Sci. Part A Polym. Chem., 2006, 44, 801-809.

7 Organic soluble CD-based IMWs, see; M. J. Frampton, G. Sforazzini, S. Brovelli, G. Latini, E. Townsend, C. C. Williams, A. Charas, L. Zalewski, N. S. Kaka, M. Sirish, L. J. Parrott, J. S. Wilson, F. Cacialli and H. L. Anderson, Adv. Funct. Mater., 2008, 18, 33673376.

8 J. Terao, S. Tsuda, Y. Tanaka, K. Okoshi, T. Fujihara, Y. Tsuji and N. Kambe, J. Am. Chem. Soc., 2009, 131, 16604-16605.

9 J. Terao, Y. Tanaka, S. Tsuda, N. Kambe, M. Taniguchi, T. Kawai, S. Saeki and S. Seki, J. Am. Chem. Soc., 2009, 131, 18046-18047.

9510 For synthetic details, see: T. Kaneda, T. Fujimoto, J. Goto, K. Asano, Y. Yasufuku, J. H. Jung, C. Hosono and Y. Sakata, Chem. Lett., 2002, 31, 514-515.

11 S. Tsuda, J. Terao and N. Kambe, Chem. Lett., 2009, 38, 76-77.

12 For nomenclature of rotaxanes, see: A. Yerin, E. S. Wilks, G. P. Moss and A. Harada, Pure Appl. Chem., 2008, 80, 2041-2068.

13 (a) H. Yamakawa and M. Fujii, Macromolecules, 1974, 7, 128-135; (b) H. Yamakawa and T. Yoshizaki, Macromolecules, 1980, 13 633-643.

14 (a) A. Acharya, S. Seki, A. Saeki, Y. Koizumi and S. Tagawa, Chem. 105 Phys. Lett., 2005, 404, 356-360. (b) A. Saeki, S. Seki, T. Takenobu, Y. Iwasa and S. Tagawa, Adv. Mater., 2008, 20, 920-923. (c) T. Amaya, T. Moriuchi, K. Nakamoto, T. Nakata, H. Sakane, A. Saeki, S. Tagawa and T. Hirao, J. Am. Chem. Soc., 2009, 131, 408-409.

15 K. Sugiyasu, Y. Honsho, R. M. Harrison, A. Sato, T. Yasuda, S. Seki 110 and M. Takeuchi, J. Am. Chem. Soc., 2010, 132, 14754-14756. 